\title{
ПРИНЦИП ПЛЮРАЛИЗМА В СОВРЕМЕННОЙ ФИЛОСОФИИ
}

\begin{abstract}
А.И. Абдула
Наши рассуждения в данной статье преследуют несколько целей. Мы хотим акцентировать внимание на проблеме оснований и на тех парадоксах, которые составляют сущность этой проблемы. Найдя удовлетворяюшее нас решение в плюрализме, мы обсудим продуктивность такого решения, и покажем, в чем состоит его отличие от релятивизма. И наконец, мы подробно остановимся на специфике оснований в контексте рассмотрения феномена рациональности.

Начнем с того, что можно было бы назвать рефлексией. Термин достаточно многозначен, и очевидно, содержание, которое он получает в контексте исследования, нуждается в дополнительных комментариях с нашей стороны. Не вдаваясь в историю проблемы, констатируем, что рефлексию в нашем понимании следует рассматривать как рассуждение, направленное на анализ некоторых особенностей применения того, что принято называть философским методом. Эта вступительная часть рефлексивна постольку, поскольку направлена на процесс собственного конструирования. Она является определяющей «точкой входа» в бесконечную цепь посылок и заключений. Хотя собственно метод и не является основным объектом нашего исследования, данную проблему следует рассмотреть в числе первых, в то же время «исследования» исключающие упоминания о границах и основаниях, не такая уж и редкость. Можно еще добавить, что в некоторых из них отвергаются какие бы то ни было ограничения, выступающие в роли добровольно взятых на себя обязательств соблюдать определенные «правила игры».
\end{abstract}

Рамки или границы философского исследования связаны с исхо-

Актуальні проблеми духовності

(Відп. ред.: Я.В. Шрамко)

Кривий Ріг (2006), 54-64 
дными принципами (назовем их аксиоматическим базисом) и методами получения на их основе нового «знания». Следует уточнить, что о базисе или основаниях мы говорим в гносеологическом или даже логическом аспекте. Онтологический же аспект заставляет нас скорее говорить о причинах. Такой подход предлагает нам, например, Артур Шопенгауэр, который, очевидно, не удовлетворен тем смешением причин и оснований, которое находит у своих предшественников.

Проблема первопричин и оснований находится в центре философских дискуссий, еще со времен первых философов. Многие считали необходимым уделить должное внимание поиску надежного фундамента для своих систем или, по крайней мере, возникающим в связи с этим философским проблемам. Проблеме оснований посвящена докторская диссертация Шопенгауэра, в которой он помимо компетентного анализа посвященных данному вопросу работ, формулирует, (ссылаясь на Вольфа), закон достаточного основания: «ничто не существует без основания того, почему оно есть» $[12$, с.9]. Предложенный Шопенгауэром вариант разрешения проблемы представляется нам довольно показательным.

Следует уточнить, что процесс познания Шопенгауэр интерпретирует в духе Канта: «Наше познающее сознание, выступая как внешняя и внутренняя чувственность (рецептивность), рассудок и разум, распадается на субъект и объект и сверх этого не содержит ничего. Быть объектом для субъекта и нашим представлением одно и тоже. Все наши представления - объекты субъекта, и все объекты субъекта - наши представления» [12, с.24]. Эти представления находятся между собой в закономерной связи, которая носит априорный характер. Так как существует эта связь, то ничто не существует изолированно, само по себе.

В зависимости от типа представлений, Шопенгауэр выделяет корни закона достаточного основания: закон становления (закон причинности), закон основания познания (основанный на связи между понятиями), закон основания бытия (как математическое отношение, имеющие трансцендентальное происхождение) и закон мотивации (воли). Однако закономерно возникает вопрос о необходимости обоснования или доказательства закона достаточного основания. Шопенгауэр замечает, что предыдущие попытки доказать его оказались тщетными и приходит к следующему выводу: «К тому же искать доказательство закона достаточного основания - бессмыслица особого рода, свидетельствующая о недостатке благоразумия. Ведь каждое доказательство есть установление основания для высказанного суждения, кото- 
рое тем самым и получает предикат истинного. Именно выражением этой необходимости в основании для каждого суждения и является закон достаточного основания. Поэтому тот, кто требует доказательства этого закона, уже предполагает этим его истинность и именно на этом предположении основывает свое требование. Следовательно, образуется круг, ибо требуется доказательство права требовать доказательства» [12, с. 22].

Если имеется определенный набор оснований, то на онтологическом уровне мы можем попытаться найти причину, по которой, скажем, эти основания у конкретного индивида те, а не иные. Такая замкнутость, даже если ее удалось избежать в гносеологическом аспекте, является неотъемлемым атрибутом межуровневого взаимодействия и фактически отображает парадокс «объект-субъект». По сути, закон достаточного основания, как его понимает Шопенгауэр, - априорный закон. Его истинность не подвергается сомнению, она принимается как данность. В таком случае мы можем сказать, что закон этот является объектом философской веры.

Для нас очевидно, что, во-первых, существуют несводимые друг к другу исходные принципы и методы. Во-вторых, любая попытка проанализировать базис и методы подразумевает имманентные субъекту собственный набор постулатов и методов, т. е. по сути своей циклична и рефлексивна. В-третьих, существуют дополнительные требования, которое закрепляет статичность постулатов и методов.

Марксистская интерпретация проблемы оснований возвращает нас к формулировке «основного вопроса философии». Тем не менее, помимо соотношения материального и духовного существует целый ряд философских проблем, любая из альтернатив разрешения которых, может рассматриваться в качестве основания для дальнейшего развития теории или модели, и которые субъект явно или неявно принимает. В контексте данного рассуждения, помимо прочего, нам представляется важным выделить парадокс объект-субъектного взаимодействия и дихотомию «порядок-хаос».

Хотя, казалось бы, основания не требуют доказательств по определению, они, как правило, снабжаются набором пояснений или «подтверждений». Некоторые исследователи склонны соотносить попытки философов «пояснить» основания с психологической потребностью восполнить недостаток обоснованности верования (см. [1]). В рационалистической традиции подтверждающую аргументацию связывают с апелляциями к разуму и чувствам, в иррационалистической - с эмоциональными и аффективными состояниями, «вчувствованием», «вжи- 
ванием» в ситуацию.

Из ряда проблем, примыкающих к вопросу об основаниях и причинах выделим: проблему самоприменимости или рефлективности, проблему определения основных терминов и проблему регресса. В ходе нашего рассуждения мы акцентируем внимание на классической проблеме цикличности, - того «замкнутого круга», в который попадает всякий, кто пытается обосновывать основания или причины

Самоприменимость может использоваться как один из аргументов, подтверждающих состоятельность теории, в случае если теория претендует на универсальность или же, так или иначе, затрагивает вопросы, связанные с собственным становлением. Примером может служить «рефлексивный» принцип «сильной программы» социологии знания: «Социология знания должна быть рефлексивной. В принципе ее объяснительные конструкции должны быть применимы к самой социологии. $\langle\ldots\rangle$ Это очевидное требование, так как в противном случае социология являла бы собой опровержение собственных теорий» [2, c. 166-167]. Однако попытка самообоснования может привести к тому, что теория окажется внутренне противоречивой. Подобная проверка через самообоснование зачастую служит объектом критики, которая направлена на «дискредитацию» теории. Например, «некритическая» версия рационализма, как считает Карл Поппер, должна быть отброшена вследствие применения к себе собственных же принципов. В то же время Поппер, в отличие от Блура, вовсе не требует для своих теорий самообоснования. Критики же социологии знания утверждают, что упомянутая цикличность неизбежно приводит к тому, что теория сама себя опровергает. Данное затруднение может быть рассмотрено в рамках анализа одного из наиболее известных парадоксов - парадокса лжеца. Один из способов разрешения данного парадокса заключается в том, чтобы отделять высказывания о языке от высказываний об объективной реальности, таким путем разделяя предметный язык и метаязык. По сути, упомянутая социология знаний игнорирует метауровень.

Необходимость рассматривать всеобие основания связана с невозможностью доказать все утверждения. Регресс начинается там, где доказательства будут требовать доказательств, а основания - оснований. Но регресс может быть связан и с попытками, через дефиниции основных понятий, прояснить и уточнить их значения, а значит, и прийти к общим основаниям. Необходимо ли уточнять Значения терминов? Шопенгауэр, например, утверждает следующее: «Наибольшую, достигаемую точным определением значения каждого выражения по- 
нятность я считаю в философии требованием безусловно необходимым, чтобы предотвратить заблуждение и умышленный обман и сделать каждое полученное в области философии познание прочным достоянием, которое уже не может быть утрачено из-за открытого впоследствии недоразумения или двусмысленности» [12, с. 8]. В выдвинутом Шопенгуэром требовании ясности можно выделить два аспекта.

Первый связан с упомянутой выше традицией давать точные определения понятий, которая берет начало еще от Аристотеля. С резкой критикой этой доктрины выступает в частности Карл Поппер, который считает, что этот подход оказал пагубное влияние на философию и в последствии предопределил попытки переноса философских проблем в сферу лингвистических головоломок (речь идет о теории Витгенштейна).

Второй аспект связан с требованием интеллектуальной честности и ясности высказываний. Ярким примером несоблюдения этого требования (с точки зрения Поппера) могут служить философские труды Гегеля. Но как же добиться четкости и ясности, не стремясь к достижению «наибольшей точности определений»? Поппер утверждает, что термины должны оставаться неопределенными и как можно менее нагруженными, так чтобы утверждения не зависели от их значений (как это, по его мнению, происходит в современной науке). В противном случае регресса определений не избежать [8, с. 19].

Парадоксы, связанные с проблемой оснований, заставляют философов говорить о парадоксах рациональности вообе и научной рациональности в частности (см. [10]). Известный российский философ В.Н. Порус, пытаясь найти основания рациональности, приходит к выводу, что рациональность - противоречивый феномен. Но может ли быть рациональность противоречивой? Казалось бы, логика утверждает, что нет. Но тогда стоит задаться вопросом о рациональных основаниях логики и о том, тождественны ли логика и рациональность. Так, если научную рациональность приравнивать к логике, рассуждает Порус, то требование обоснования рациональности сводится к требованию обоснования логики. Однако основания логики должны быть внелогическими, иначе это означало бы своего рода «самообоснование», а значит - запрещенное движение по замкнутому кругу. Cреди вариантов разрешения этого затруднения Порус выделяет, как самый радикальный, предложенный Аристотелем - считать законы логики законами бытия. Однако он не является удовлетворительным, поскольку онтология превращается при этом в онто-логику, вопрос и ответ меняются местами. Имеется другой путь, который предложи- 
ли логики в 20-м веке. Он подразумевает существование мета-логики (об этом уже говорилось выше), как логической теории, формулирующей правила построения обосновываемей ею логической системы. В свою очередь, мета-логика обосновывается мета-мета-логикой и так далее. Но, чтобы избежать регресса необходимо остановиться и не требовать более обоснований, в соответствии с требованиями практического удобства и простоты. Это ведет к переформулировке проблемы в духе прагматизма, а значит выбор последних оснований радикальным образом субъективизируется. Таким образом, делается вывод о том, что ни проблема обоснования логического, ни проблема обоснования рационального не могут быть решены ни через взаимоопределения, ни через их независимое определение, если при этом не выходить за рамки «логического» и «рационального».

Непосредственная формулировка оснований связана с теми, кого принято называть философскими авторитетами, или «основоположниками». Критический анализ и развитие их идей - дело «исследователей» (см. [1]). Принадлежность к той или иной философской парадигме проявляется не только в ярко выраженной преемственности содержания, развития и переосмысления, сформулированных авторитетными философами идей, но и в форме и в стиле изложения, в системе «позитивных» ссылок, апелляций к работам авторитетных философов или их последователей. «Негативная» ссылка неявно отрицает принадлежность к соответствующему течению, а следовательно и авторитету. «Нейтральная» ссылка не несет эмоциональной нагрузки и носит декларативный, информативный характер. «Бессылочный» вариант так же встречается, хоть он и не слишком распространен и связан или с чисто техническим не соблюдением этого требования, или же с определенными претензиями автора. И хотя призывы игнорировать авторитеты время от времени звучат в философском сообществе, избежать этого никак не удается (очевидно, такой призыв будет принят, если он будет исходить от авторитетной личности). В этой связи будет уместно вспомнить высказывание Витгенштейна в предисловии к «Логико-философскому трактату» [3]: «Я не хочу судить о том, в какой мере мои усилия совпадают с усилиями других философов. Ведь написанное мною не претендует на новизну деталей, и я потому не указываю никаких источников, что мне совершенно безразлично, думал ли до меня кто-либо другой о том, о чем думал я».

Характерно, что отсутствие единства во мнениях относительно оснований, рассматривалась, как правило, в качестве свидетельства некого нездорового состояния философии в целом. В такой ситуации 
«очевидный» выход - объявить собственные принципы истинными, а основания конкурентов - ложными и попытаться создать философскую систему, претендующую на универсальность (методы элиминации «ложных» парадигм здесь могут быть самыми разными). В противоположность такому подходу, некоторые еще в древности предложили вообще отказаться от поисков истины в одном или во всех возможных направлениях - проблема оснований в философии зачастую представлялась ими как одна из предпосылок агностицизма.

Тем не менее, существуют подходы, которые допускают возможность сосуществования нескольких парадигм или «концептуальных каркасов». Среди этих подходов нам представляется важным выделить релятивизм и плюрализм. Проблема плюрализма тесно связана с вопросом о сущности и статусе философии. С одной стороны, плюрализм зачастую отождествляют с релятивизмом и иррационализмом, a c другой - противопоставляют догматизму и тому же релятивизму. Наконец общефилософский плюрализм противопоставляется плюрализму внутринаучному.

Под философским плюрализмом мы понимаем принцип, который утверждает равное право на существование различных, иногда противоположных философских оснований. Плюрализм тесно связан с критическим методом и критическим рационализмом. Он требует критичности и беспристрастности по отношению к собственным основаниям и, в равной степени, к основаниям альтернативных философских концепций. Плюрализм - важная предпосылка рационального способа мышления. Рассел определяет философию, как «способ размышления о предметах, точное знание о которых невозможно» [11, с.83]. Но «там, где уверенность недостижима, рациональный человек придаст наибольшее значение наиболее возможному мнению в тоже время, удерживая другие, имеющие ощутимую вероятность, в своем уме, как гипотезу, которую будущие свидетельства могут подтвердить как более предпочтительную» $[11$, с. 90-91]. В то же время, проблема объективности факта для философии не может быть решена однозначно.

В нашем представлении плюрализм противопоставляется догматизму и слепой вере. Признание «единственно верным» и «подлинно истинным» того или иного подхода в философии крайне опасно и может привести к пагубным последствиям. Не случайно Ойзерман в статье, посвященной анализу марксисткой философии, приходит к выводу, что одна из ее проблем - догматичность, некритичность по отношению к собственным основаниям: «днако то обстоятельство, что основные положения марксизма и его философии были превраще- 
ны в догмы чрезвычайно сковывало развитие диалектического материализма, исключая его творческое взаимодействие с другими философскими учениями и нередко приводило не только к заблуждениям, но и к фактическому отступлению от принципов материалистической диалектики» [7, с.31]. Так возник вопрос о допустимости (и даже необходимости) плюралистического подхода внутри самой марксистской философии (см. [6]). А.А.Никифоров считает, что философия не может отождествляться с наукой, а предъявляемые к философии требования формулировать общезначимые истины не только выглядят абсурдно, но и могут нанести значительный вред, как философии, так и науке. «Философия не была, не является, и по-видимому, никогда не будет наукой. Осознание этого обстоятельства будет иметь многочисленные и благотворные следствия для нашей культуры» [5, с. 298]. Перефразировав Т. Куна, Никифоров утверждает, что именно в плюрализме заключается главное отличие философии от науки.

Во второй половине XX века, когда холодная война поставила мир на грань ядерной катастрофы, выживание человечества была напрямую связано с возможностью осуществления рационального диалога. Причину опасной конфронтации Рассел усматривает в фанатичной вере в догматические принципы: «Я думаю, что напряженность, существующая в отношениях между Востоком и Западом, и угрожающая всем нам, является в основном следствием фанатической веры в коммунизм или антикоммунизм, смотря о ком идет речь. Они верят в них таким образом, который я называю фанатическим, то есть предотвращение того, что они считают злом в другой стороне, более важно для них, чем даже продолжения существования человеческой расы, и это фанатизм» $[11$, с. 174-175]. Философы зачастую не менее радикальны, чем политики. Возможно, в глобальном масштабе это не представлялось бы нам значительным, если бы не четко выраженная взаимообратная связь между этими сферами. В философских дискуссиях плюрализм находит свое проявление не только в способности критиковать и выслушивать критические аргументы в свой адрес, но и в толерантности по отношению к оппоненту.

Распространению идей философского плюрализма на постсоветском пространстве способствовали попытки осуществить переход к плюрализму в политической сфере (очевидно, что политический плюрализм подразумевает идеи свободы, равенства и демократии). Выход за рамки догматизма в философии означал для одних возможность свободно высказывать свою точку зрения, а для других - необходимость переосмысления устоявшихся подходов и принципов. К сожале- 
нию, следует констатировать, что «противодействие» догматизму зачастую порождает не только и не столько плюрализм, сколько релятивизм и анархию.

Если там, где существуют фундаментальные философские проблемы, существуют несводимые друг к другу основания, которые, по сути, являются объектом веры, то возникает вопрос о релятивности истины при переходе между парадигмами и невозможности диалога между их представителями. В работе «Миф концептуального каркаса» (см. [9]). Карл Поппер связывает такой релятивизм с иррационализмом, который исключает возможность взаимопонимания между представителями различных «концептуальных каркасов». Эта проблема, особенно в случае, если основания связываются с идеологией, политикой или религией, зачастую выходит за рамки чисто философского рассмотрения, приобретая совершенно иное, сугубо практическое содержание.

Очевидно, во все времена те, кто называет себя учеными, стремились к получению знания (подразумевается, что знание-всегда истинно). Вера ученых - это, помимо прочего, вера в то, что их методы позволяют получить истину или, по крайней мере, приблизиться к столь желанному результату. Карл Поппер предложил критерии рациональности, в соответствии с которыми, ученый в вопросах аргументации и объективности, если и не отождествляется с философомрационалистом, то по крайней мере, имеет с ним много общего.

Ученик Поппера Имре Лакатос выделил несколько подходов к проблеме обоснования знания в научной (рационалистической) традиции, которые он рассматривал в исторической ретроспективе [4]. Прежде всего, это «джастификационизм», который требует от науки доказательной обоснованности, составляющих ее высказываний. На смену классическому джастификационизму, приходит пробабилизм, который заменяет понятие доказательной обоснованности высокой степенью вероятности. Следующий этап - появление догматического или «натуралистического» фальсификационизма. Согласно нему, все теории в одинаковой степени гипотетичны и любая из них может быть опровергнута экспериментом. Лакатос считает, что этот тип фальсификационизма основан на двух ложных посылках - «натуралистической концепцией наблюдения» и «учении о доказательном обосновании путем наблюдения». Методологический фальсификационизм, который соединяет постоянный критицизм с фаллибилизмом, более либерален и является по своей сути разновидностью конвенционализма. Вслед за Поппером констатируя несостоятельность как классического джастификационизма, так и пробабилизма, Лакатос противопоставляет свою 
позицию не только «наивному» фальсификационизму, поддерживая критику со стороны Куна, но и некоторым аспектам фальсификационизма «методологического». Взамен Лакатос предлагает «утонченный» методологический фальсификационизм, в котором наличие добавочной информации и ее подтверждений у новой теории, по сравнению со старой, является решающими аргументами в пользу новой теории. Рассуждения Лакатоса вполне могут быть применимы и к некоторым философским концепциям. Для нас важно, что во-первых, они иллюстрируют (пусть и не в полной мере) эволюцию методологических подходов, а во-вторых, проясняют тенденцию перехода от подтверждаемости и обоснованности к идее опровергаемости, высказанной Карлом Поппером.

Поппер часто говорит о столкновении культур и о том, что критический (а значит и рациональный) подход поможет сторонам избавиться от своих предрассудков. Критическая дискуссия должна противопоставляться дискуссии об основаниях, поскольку эта проблема при любом подходе не может быть разрешена однозначно. В рационалистической традиции правильный метод противопоставляется ошибочному методу критики. Ошибочный метод критики начинается с вопроса о принципах или аксиомах, на которых основывается наш тезис или теория. Тем самым он ведет к догматизму, регрессу или релятивизму. Правильный метод, как отмечает Поппер, учитывает погрешимость наших теорий и стремится сделать их лучшими. Он начинается с вопроса о том, какие последствия будет иметь для нас данная теория.

Мы предлагаем рассматривать поливариантность философских подходов как следствие фундаментальных парадоксов, однозначное рациональное разрешение которых не представляется возможным. Таким образом, имеем дело с концептуальными каркасами, основания которых суть объекты веры. Мы считаем, что попытки редуцировать аргументацию к основаниям - это ошибочный путь. В противовес такому подходу, мы предлагаем использовать плюралистический подход, который не только допускает существование различных парадигм, но и делает возможной и необходимой дискуссию между их представителями, а значит и достижение истины.

\section{1 Литература}

[1] Баранеи Н.Г. О вере, репутации и авторитетах в философии // Вопросы философии. - 2004. - № 4. - С. 54-58. 
[2] Блур Д. Сильная программа в социологии знания // Логос.2003. 一№ 5-6(35). - C. 162-185.

[3] Винтгенштейн Л. Логико-философский трактат. - М., 1958.

[4] Лакатос И. Фальсификация и методология научно-исследовательских программ. - М.: Медиум, 1995.

[5] Никифоров Л.А. Философия как личный опыт // Заблуждающийся разум? Многообразие вненаучного знания. - М.: Полиздат, 1990. - C. 296-304.

[6] Ойзерман Т.И. Исторические судьбы плюрализма философских идей. // Вопросы философии. - 1991. - № 12. - С. 3-14.

[7] Ойзерман Т.И. Опыт критического осмысления диалектического материализма // Вопросы философии. - 2000. - № 2. - С. 3-31.

[8] Поппер K. Миф концептуального каркаса // Логика и рост научного знания. - М.: Прогресс, 1983.

[9] Попnер K.P. Відкрите суспільство та його вороги, Т.2. Спалах пророцтва: Гегель, Маркс та послідовники: пер. 3 англ. О. Буценко. - К.: Основи, 1994.

[10] Порус В.Н. Рациональность; Наука; Культура. - М., 2002.

[11] Рассел Б. Искусство мыслить: пер. с англ. Козловой Е.Н., Назаровой О.А., Сычевой С.Г. - М.: Дом интеллектуальной книги, 1999.

[12] Шопенгауэр А. О четверояком корне... Мир как воля и представление. Т. 1. Критика кантовской философии: Пер. с нем./ Ин-т философии. - М.: Наука, 1993. 